Portland State University

PDXScholar

World Languages and Literatures Faculty

Publications and Presentations

$1-2011$

\title{
Second Language Development Theories and Technology-mediated Language Learning
}

\author{
Steven L. Thorne \\ Portland State University \\ Bryan Smith \\ Arizona State University
}

Follow this and additional works at: https://pdxscholar.library.pdx.edu/wll_fac

Part of the Communication Technology and New Media Commons, and the First and Second Language Acquisition Commons

Let us know how access to this document benefits you.

\section{Citation Details}

Thorne, S. L., \& Smith, B. (2011). Second language development theories and technology-mediated language learning.CALICO Journal, 28(2), 268-277.

This Article is brought to you for free and open access. It has been accepted for inclusion in World Languages and Literatures Faculty Publications and Presentations by an authorized administrator of PDXScholar. Please contact us if we can make this document more accessible: pdxscholar@pdx.edu. 


\title{
Second Language Development Theories and Technology-mediated Language Learning
}

\author{
Steven L. Thorne \\ Portland State University \& University of Groningen \\ BRYAN SMITH \\ Arizona State University
}

Information and communication technologies have never been more interesting due in large part to their intimate integration into everyday life. Second and foreign language researchers and educators have long recognized the potential of technology to provide access to input and rehearsal (recordings, tutorials and drills), to amplify possibilities for personal expression (text and media processing), to extend existing and enable new opportunities for interpersonal communication (synchronous and asynchronous messaging), and most recently, considerable interest has been focused on social media and social networking environments that have de facto become fused with the activity of real (and not merely 'virtual') life.

How these many new environments and tools potentially support meaningful language use, committed interpersonal engagement, and more narrowly defined actions such as rehearsal and practice, are some of the perennially asked questions that come to inform the ultimate issue of importance for language researchers and educators alike: which forms of communicative activity articulate with what rates, quantities, and qualities of second language development? Contemporary research in second language acquisition provides many responses to this question and provides a wide array of approaches and methodologies, many of which have been applied to new and emerging media contexts. At the same time, a wide number of academics from disciplines such as computer and information science, anthropology, communication, psychology, sociology, philosophy, and education, to name only a few, have turned their attention toward new media and their implications for society, social networks, organizational and interpersonal communication, recreation, learning, and by extension, teaching.

Technology-mediated language use and learning, which we will refer to using its historically most frequent (if also increasingly anachronistic) acronym CALL (computer-assisted language learning), has a vibrant and approximately fifty-year history as a discrete sub-field of applied linguistics, one that spans from early technologies such as the mainframe computer in the 1960 s to cloud computing and social media as we enter the second decade of the new millennium (for various reviews of CALL history, theory and research, see Bax, 2003; Hubbard, 2009; Kern, 2006; Thorne, 2008; Warschaeur \& Healey, 1998; for a review of SLA and CALL, see Chapelle, 2009). As the use of CALL grew over time, a variety of second language acquisition theories came to inform pedagogical practice and innovation as well as research on the effectiveness and outcomes of technology mediated practice and communication. However, it is also the case that many CALL specialists have exhibited the understandable tendency to become focused on the technology while perhaps attending less assiduously to emerging trends and current findings in second language acquisition, and more broadly, from research on human development.

CALICO Journal, 28(2), p-p 268-277.

(C) 2011 CALICO Journal 
It is in acknowledgement of just this tension, between a focus on keeping up with emerging technologies, digital environments, and the social practices they mediate on the one hand, and remaining well versed in contemporary approaches to second language development on the other, that initially sparked the flame that became this project. The precise genesis of this special issue of the CALICO Journal, titled "Second Language Acquisition Theories, Technologies, and Language Learning," dates to a meeting of the Second Language Acquisition and Teaching (SLAT) Special Interest Group (SIG) that took place at the 2008 CALICO conference. The SLAT SIG participants at this meeting, a number of whom were first time attendees, discussed possible functions the SIG could serve over the year to come. The key issue to emerge was that many in the group felt much more comfortable with technology and technology-related pedagogies than they did with theories and research associated with second language acquisition. A perceived disconnect between SLA and CALL was also mentioned, which suggested that at least for some language-technology specialists, the sub-field of CALL had become its own self-contained context, operating somewhat independently from SLA, language learning more generally, and yet more broadly, from the robust research traditions that address questions of human development on phylogenetic and ontogenetic scales, all of which inarguably contribute to better understanding and utilizing new and emerging media for purposes of additional language use and learning.

This revelation of the voiced need to re-unite SLA theory with technology-mediated language education led to the decision to convene a panel format event at the CALICO 2009 annual conference. CALICO affiliated researchers who work within various SLA frameworks/theories were invited to give presentations relating an established SLA approach to CALL research, development, and practice. Due to the time limitations of a single one and a half hour time slot, four representative SLA perspectives were selected. With a metaphorical flow from micro to macro, and drawing a continuum from brain local phenomena to largely social and environmental emphases, a panel was convened of four researchers, working within diverse SLA frameworks, who have addressed as part of their research technology-mediated language learning. The panel participants were Scott Payne (psycholinguistics of SLA), Bryan Smith (interaction approach to SLA), Steven Thorne (sociocultural approaches to SLA), and Leo van Lier (ecological approaches to SLA). Each presenter was asked to provide a concise description of, and to intellectually situate, their designated SLA approach, to outline important research and pedagogical findings produced from this framework, and to address the question of how their respective SLA theory informs pedagogical practice in CALL and technology design. The brief abstracts for each contribution, reproduced below, illustrate the primary goal of the special issue - to elucidate the primary features and orientations of established approaches to SLA research with particular attention to their application to technology-mediated language learning.

Psycholinguistics, SLA, and Technology (Scott Payne): Investigating second language acquisition and CALL from a psycholinguistic perspective entails examining how language learners process, store, and retrieve information from memory and how cognitive capacity impacts acquisition and influences performance. This paper will provide an overview of psycholinguistic approaches to SLA research highlighting research findings relevant to the field of CALL. This discussion will include some of the challenges and opportunities for researchers interested in employing psycholinguistic methods for studying SLA in classroom and computer-mediated contexts.

The Interaction Approach and CMC (Bryan Smith): The Interaction Approach (IA) in second language acquisition studies suggests that there is a link be- 
tween interaction and learning. This approach focuses on three major components of interaction - exposure (input), production (output), and feedback. Many CALL researchers have adopted this theoretical perspective in exploring the relationship between CMC and instructed second language acquisition, exploiting many of the argued affordances offered by this medium in relation to the key tenets of the IA. This paper will provide a conceptual overview of the IA and explore specifically how CALL researchers have sought to study SLA from this theoretical perspective. We will discuss several methodological hurdles facing researchers engaged in this type of research and will offer some suggested strategies for conducting sound SLA/CALL research from an IA.

Sociocultural Approaches to SLA and Technology (Steven Thorne): Sociocultural approaches (SCT) to second language acquisition draw from a tradition of human development emphasizing the culturally organized and goal-directed nature of human behavior and the importance of external social practices in the formation of individual cognition. This paper describes the principle constructs of the theory, including mediation, internalization, and the zone of proximal development, and will describe technology-related research in these areas. Vygotskian SCT shares foundational constructs with distributed and situated cognition, usage-based models of language acquisition, language socialization, and ecological approaches to development, all of which have contributed to new applications of SCT in the areas of language research and pedagogical innovation. A discussion of methodological challenges and current practices will conclude the presentation.

Ecological Approaches to SLA and Technology (Leo van Lier): Ecological approaches to SLA are premised on a holistic view of human-world interrelations and the notion of affordance-effectivity pairings that help to better understand human activity and functioning. To many educators, technology and ecology are irreconcilable opposites. Yet, educationally speaking, they turn out to be perfectly compatible. This presentation examines the ways in which the Internet is an emergent resource, a social tool, and a multimodal repository of texts. The ecological affordances of CALL will be illustrated in terms of activity through, with, at and around computers.

At the conclusion of the CALICO 2009 annual conference, the presenters were encouraged to guest edit a special issue of CALICO Journal that would take the same name and theme as the panel: Second Language Acquisition Theories, Technologies, and Language Learning. We (Steve Thorne and Bryan Smith) accepted this invitation, developed a proposal, and began publicizing the open call for papers. Given that SLA theories are numerous, diverse, and variably address cognitive, psychological, social, cultural, environmental, and identity/performativity related processes, we (the editors) realize that the contributions to this special issue are only partially inclusive of the many viable SLA theories available. However, we are also gratified to see that a significant number of the many SLA approaches we listed in the call for papers have come to be present in the current issue.

\section{THIS ISSUE}

Each of the eleven articles in this special issue address second language development in technology-mediated contexts from a distinctive developmental and/or linguistic perspective, and in some cases, authors synergistically bring together related frameworks and methodologies. 
Each article provides a concise description of the SLA approach and/or research methodology employed in the study, discusses important research and pedagogical findings produced from this framework, and addresses the strengths and limitations of the theory in relationship to applied linguistics research and pedagogical practice. In our summary of these articles, we both review the key elements and findings of the studies as well as highlight the core aspects of the SLA approach that was utilized.

Gebhard, Shin and Seger bring together the often-paired frameworks of system-functional linguistics (SFL), for analysis of the social-semiotic functions of language, and Vygotskian sociocultural theory as their approach for analyzing learning, to examine the emergent literacy development of a young English language learner (for a discussion, see Hasan, 1992). The intervention involved a blog-mediated writing curriculum informed by SFL and genre-based pedagogy (Halliday \& Matthiessen, 2004; Schleppegrell, 2004; Martin \& Rose, 2008). SFL unites linguistic and social phenomena and has made prodigious contributions to the functional analysis of language structure and use. To paraphrase Gebhard and co-authors, SFL posits that human languages develop to manage three metafunctions; 1 ) ideational, representing ideas and experiences, 2) interpersonal, managing social relations with others, and 3) textual, organizing the flow of communication to make discourse coherent and cohesive. SFL's emphasis on the use of language to learn about and invoke social realities aligns with Gebhard, Shin and Seger's application of the Vygotskian concepts of mediation and appropriation, which they employ to analyze the processes their focal participant experienced while becoming textually literate in English. The findings from the study indicate that SFL informed genre-based instruction, coupled with the affordances of blog-mediated writing opportunities, supported L2 development for this at-risk student.

Utilizing conversation analysis (CA), González-Lloret presents a longitudinal case study of a Spanish L2 learner engaged in interaction with an L1 Spanish speaker. CA is the study of consistently realized interactional patterns and embodied practices that constitute everyday communication in informal as well as institutional contexts. As an approach to the analysis of talk-in-interaction, CA has helped to reveal both language-culture specific interactional patterns (Schegloff, Koshi, Jacoby, \& Olsher, 2002) as well as seemingly universal dynamics of turn-taking (Stivers et al., 2009). With roots in ethnomethodology and sociology, CA was initially developed to address questions of sequence organization and the maintenance of intersubjectivity (i.e., a shared definition of situation) in the context of co-present or audio (telephone) interaction. González-Lloret describes existing CA for SLA research (e.g., Kasper, 2009; Markee, 2008) and then extends the use of CA to computer-mediated interaction. In particular, González-Lloret assesses the necessary modifications and adjustments that need to be taken into account given that pivotal aspects of $C A$, such as transition relevance places and sequence organization to name only two, are rendered differently in interactive textually mediated communication. The findings from González-Lloret's study convincingly support the use of CA as a method for analyzing the dynamics of computer-mediated interaction. This research also demonstrates CA's usefulness as a method for tracking changes in participation and interactional patterns as markers of language development.

Reinhardt and Zander's article provides an empirical examination of the use of a social-networking site (SNS) by students enrolled in an Intensive English Program. The project utilizes language socialization (Duff, 2007), situated learning (Lave \& Wenger, 1991), and the bridging activities model (Thorne \& Reinhardt, 2008) as approaches to design and interpret an intervention to foster critical awareness of English language communicative practices common to SNSs and participation in social network games. Language socialization approaches propose a model of $L 2$ development that unites becoming a speaker of a language with participation in particular speech communities. Interactions with experienced members of a community help novices develop discrete linguistic competencies as well as sensitivity to normative patterns of 
interaction (e.g., Ochs, 1993). The implementation results were somewhat surprising. While the majority of the students were already frequent users of SNSs and participated vigorously in the project, others resisted the use of vernacular technologies. Reinhardt and Zander detail the risks and rewards of SNS use and in this way, provide a needed corrective to the largely optimistic literature on this topic.

In a study related to that of Reinhardt and Zander, Mills contributes to the 'social turn' in SLA (e.g., Block, 2003) and employs situated learning theory (e.g., Lave \& Wenger, 1991) to understand the use of a social networking environment by French foreign language students. Emphasizing that language learning is both a social and cognitive experience (Pavlenko, 2001) and that processes of language socialization are critical for the development of social and pragmatic competencies (e.g., Duff, 2007; Thorne, Black, \& Sykes, 2009; see also Reinhardt \& Zander, this issue), Mills follows students as they create a fictional 'global simulation community' on Facebook (see also Mills \& Péron, 2009). Guided by principles that highlight joint enterprise, mutual engagement, and shared repertoire (Wenger, 1998), the participants roleplayed as tenants in the same immeuble (apartment building) in Paris. The Facebook-based global simulation emplaced the participants in a French virtual-physical context and afforded a variety of opportunities for interpretive, creative, and interpersonal engagement within a context that emphasized self-direction, ownership, and autonomy.

In a unique synthesis of almost 100 SCMC studies spanning the last two decades, Sauro explores trends, methods, and findings across several theoretical approaches to SLA. She does this by operationalizing SLA as the development of the four competences subsumed under Canale and Swain's (1980) interpretation of communicative competence (Hymes, 1971). She discusses trends and topics that have been undertaken largely in response to Chapelle's (1997) call for our field to better incorporate theory and research methods from SLA in our explorations of the nature and effectiveness of CALL. She further organizes the studies and their findings into the following major strands within each competence: 1 . Grammatical competence; The Quantity, Complexity, and Accuracy of L2 Performance in SCMC; Facilitating Learning Processes; and Effect on Lexical and Grammatical Knowledge or Production; 2. Sociolinguistic competence; Speech Acts, Discourse Functions, and Participant Roles; Appropriacy of Form; and Language Socialization; 3. Discourse Competence; Maintaining Coherence and Cohesion in SCMC; Impact on Cohesion and Coherence in Other Modalities; and 4. Strategic Competence; Negotiating Communication Breakdown; and Enhancing Communication Effectiveness.

In an exploration of intercultural communicative competence (e.g., Byram, 1997), Chun examines online exchanges between American students of German living in the United States and German students studying English as a foreign language in Germany. Chun attends particularly to the development of intercultural pragmatics and examines two related issues in detail. The first issue, drawing upon and confirming earlier work by Kramsch and Thorne (2002), involves a close assessment of the differing discourse styles that the two student groups exhibited. Chun illustrates that the Americans, despite considerable linguistic ability, over-relied on the use of questions as a marker of curiosity and interest and expected the same from their German interlocutors. The second issue, elaborating on Ware and Kramsch (2005), was the somewhat limited success the students demonstrated in the area of reflecting on discourse pragmatics. Chun concludes that when certain types of discourse were present, such as questions that led to spontaneous and unsolicited opinions in the context of extended discussions about political and cultural themes, the interactions were valuable and contributed to students' development of translingual and transcultural competence.

Cotos uses a mixed-method design to investigate the learning potential of automated feedback, generated by a program called the Intelligent Academic Discourse Evaluator (IADE), 
and its relationship to language learning in the context of $L 2$ academic writing. Tenets drawn from the interaction approach to SLA (Gass \& Mackey, 2006; Smith, 2003) were incorporated into the design of the IADE and were also used to analyze the student responses to the IADE feedback. The interaction approach, sometimes described as research addressing 'negotiation of meaning', focuses on the four key elements of input, production and interaction, and feedback (negative evidence), which then leads to modified (and hopefully improved) output. Cotos employed a prodigious array of data collection methodologies, including multiple surveys, automated and human scored first and final drafts of compositions, screen capture, think-aloud protocols, and interviews, among other measures. The research questions, asking whether feedback from IADE supported enhanced focus on discourse form and noticing negative evidence, were answered in the affirmative and led to an overall improvement in the rhetorical quality of the participants' L2 writing.

Psycholinguistic approaches to SLA attend to issues such as language processing, multilingual lexical and supra-lexical item storage and recall, and models that attempt to describe the interrelationships between long-term memory and on-line executive functions such as attention shifting, inhibitory control, and working memory. Building on research in cognitive psychology which explores the differential effects of temporal spacing between repetitions on long-term retention of new lexical material, Schuetze and Weimar-Stuckmann report on a two-year study of German L2 vocabulary learning, which was designed to determine whether one type of rehearsal interval - uniform delay or graduated delay - would result in higher rates of short- and long-term vocabulary retention among second language learners. Using the vocabulary learning software program ViVo (Virtual Vocabulary), which recorded student activity and allowed the researchers to track the learners' progress, several sections of lowerdivision German (German 100A and 100B) rehearsed target vocabulary from each chapter and also took online and print tests at the end of each chapter, at the end of each of the two main semesters, and then again nine months and five months after having completed the first and second German courses respectively. Results suggest a trend in favor of a uniform interval in that learners who rehearsed words every two days tended to outperform participants who rehearsed words in a graduated - exponentially expanding - interval. The results are most compelling for the long-term retention test that was carried out several months after participants had rehearsed the target vocabulary. Schuetze \& Weimar-Stuckmann suggest that the results support the working of the phonological loop with the uniform interval being more efficient than the graduated interval, especially for long-term vocabulary retention.

Computer-supported collaborative L2 writing in a fully distance education format comprises the empirical context that Blin and Appel analyze using cultural-historical activity theory (CHAT) as their developmental and methodological framework. The authors outline the intellectual antecedents (e.g., Marx and Vygotsky) that have informed contemporary CHAT as it has evolved in the modern era (e.g., Engeström, 2008; Kaptelinin \& Nardi, 2006; Sannino, Daniels, \& Gutiérrez, 2009; Sawchuk, Duarte, \& Elhammoumi, 2006). CHAT analysis observes a tripartite hierarchical structure of human activity, namely 1) activities, which are societal in scope, cyclic and long-term, driven by a motive, and address the question of why something is taking place; 2) actions, which are finite in duration and describe what is being done at the level of conscious orientation toward a goal or sub-goals; and 3) operations, which are contingent on immediate social and material conditions, involve real-time processes, and that are typified by automatic and non-reflective engagement and behavior. These three analytic levels, addressing a continuum of temporal and sociological scales, are the conceptual tools that allow the analyst to incorporate divergent perspectives and types of data to form a coherent view of culturally organized systems as dynamic processes. As is the case with all Vygotskian lineage approaches, a fundamental concept is that human action is mediated by semiotic (i.e., languages and literacies) and material artifacts. Blin and Appel draw specifically on Engeström's (2008) recent work to analyze the significant and shifting roles that various 
kinds of mediating artifacts play in the organization, process, and outcomes of collaborative writing tasks.

In their article, Lai and Li critically review task-based language teaching (TBLT) as it is used in technology rich environments (e.g., Ellis, 2003; Skehan, 2003). The foundation of TBLT rests on the interaction approach to SLA and the broader notion that constructing specifics kinds of experiences and providing appropriate feedback can channel learners' awareness toward form, which in turn may lead to modified production. The authors present an exhaustive review of technology-related SLA research and provide in-depth treatments of the contributions and challenges of TBLT to CALL research and practice.

In the final article of the special issue, Kessler and Bikowski describe the importance of SLA training for teachers in preparation, paying special attention to key concepts and research findings from a variety of SLA approaches and their integration into computer-mediated curricular materials. The SLA course emphasized the interaction approach (see also Cotos, this issue), among other traditions, and included the use of Gass and Selinker's (2008) SLA introductory volume. The CALL course which followed the next term began with Egbert, Hanson-Smith, and Chao's (2007) eight 'optimal conditions' for SLA, which was used to present a practice-oriented distillation of core SLA principles. The participants in the CALL course designed technology-mediated curricula and then used the eight 'optimal conditions' as an evaluation rubric. Results of a survey of the CALL course participants indicated that the SLA informed evaluation rubric helped the teachers in preparation to make informed decisions regarding the design of CALL activity types and tasks.

\section{NEXT STEPS: CONTINUING THE DIALOGUE}

As many technology researchers have remarked, CALL is both exciting and daunting due to its rapidly changing tableau of tools, environments, cultures, and expressive possibilities. Amidst the mercurial and unpredictable developments in new and social media, Hubbard (2009) makes the following observation that underscores the need to remain focused on the 'learning' aspect of the CALL acronym:

as computers have become more a part of our everyday lives - and permeated other areas of education - the question is no longer whether to use computers but how. CALL researchers, developers and practitioners have a critical role in helping the overall field of second language learning come to grips with this domain. (p. 1, italics added)

The 'how' question is certainly one that is more completely answered with support from basic research in SLA, but we feel it is important to recognize that technology and second language acquisition have a complex and dialectical relationship with one another. As has been discussed in a number of recent publications, technological advances have often co-occurred with, and potentially precipitated, conceptual shifts in SLA and theories of language and development (e.g., Lam \& Kramsch, 2003; Kern \& Warschauer, 2000); and equally, the wide spread use of information and communication technologies in educational and lifeworld contexts has escalated the need for, and attention to, SLA research as a unifying bridge between CALL theory, design, and practice. In this sense, SLA and CALL share an ecology governed by questions regarding the complex relationships between language use and language development. We hope that the articles in this special issue will support, and perhaps even modestly enhance, continuing dialogues between approaches to SLA and CALL research and practice.

In conclusion, we would like to thank the CALICO Journal for providing us with this forum and also to gratefully acknowledge the reviewers for this special issue, who, though too numerous to list here, are spread across five continents. They graciously shared a small portion of their 
lives in 2010 to help make this issue as strong as possible.

\section{REFERENCES}

Bax, S. (2003). CALL-Past, present and future. System, 31(1): 13-28.

Block, D. (2003). The social turn in second language acquisition. Washington, DC: Georgetown University Press.

Byram, M. (1997). Teaching and assessing intercultural communicative competence. Clevedon, UK: Multilingual Matters.

Canale, M., \& Swain, M. (1980). Theoretical bases of communicative approaches to second language teaching and testing. Applied Linguistics, 1, 1-47.

Chapelle, C. (1997). CALL in the year 2000: Still in search of research paradigms? Language Learning and Technology, 1(1), 19-43.

Chapelle, C. (2009). The relationship between second language acquisition theory and computer-assisted language learning. Modern Language Journal, 93, 741-753.

Duff, P. (2007). Second language socialization as sociocultural theory: Insights and issues. Language Teaching, 40, 309-319.

Egbert, J., Hanson-Smith, E., \& Chao, C. C. (2007). Introduction: Foundations for teaching and learning. In J. Egbert \& E. Hanson-Smith (Eds.), CALL environments: Research, practice, and critical issues (2nd ed.) (pp. 1-18). Alexandria, VA: TESOL.

Ellis, R. (2003). Task-based language learning and teaching. Oxford: Oxford University Press.

Engeström, Y. (2008). From teams to knots: Activity-theoretical studies of collaboration and learning at work. Cambridge: Cambridge University Press.

Gass, S., \& Mackey, A. (2006). Input, interaction and output: An overview. AILA Review, 19, 3-17.

Gass, S. M., \& Selinker, L. (2008). Second language acquisition: An introductory course (3rd ed.). New York: Routledge.

Halliday, M. A. K., \& Matthiessen, C. (2004). An introduction to functional grammar (3rd ed.). London: Edward Arnold.

Hasan, R. (1992). Speech genre, semiotic mediation, and the development of higher mental functions. Language Sciences, 14(4), 489-528.

Hubbard, P. (2009). General introduction. In P. Hubbard (ed.), Computer assisted language learning, Volume 1: Foundations of CALL. Critical concepts in linguistics (pp. 1-20). New York: Routledge.

Hymes, D.H. (1971). On communicative competence. Philadelphia: University of Pennsylvania Press.

Kaptelinin, V., \& Nardi, B. (2006). Acting with technology: Activity theory and interaction design. Cambridge, MA: MIT Press.

Kasper, G. (2009). Locating cognition in second language interaction and learning: Inside the skull or in public view? International Review of Applied Linguistics, 47, 11-36.

Kern, R. G. (2006). Perspectives on technology in learning and teaching languages. TESOL Quarterly, $40(1), 183-210$.

Kern, R., \& Warschauer, M. (2000). Theory and practice of network-based language teaching. In Warschauer, M. \& Kern, R. (Eds.), Network-based language teaching: Concepts and practice (pp. 1-19). New York: Cambridge University Press.

Kramsch, C., \& Thorne, S. (2002). Foreign language learning as global communicative practice. In D. 
Block \& D. Cameron (Eds.), Language learning and teaching in the age of globalization ( $\mathrm{pp}$. 83-100). London: Routledge.

Lam, W. S. E., \& Kramsch, C. (2003). The ecology of an SLA community in computer-mediated environments. In J. Leather \& J. van Dam (Eds.), Ecology of language acquisition (pp. 141-158). Dordrecht, The Netherlands: Kluwer.

Lave, J., \& Wenger, E. (1991). Situated learning: Legitimate peripheral participation. Cambridge: Cambridge University Press.

Markee, N. (2008). Toward a learning behavior tracking methodology for CA-for-SLA. Applied Linguistics, 29, 404-427.

Martin, J. R., \& Rose, D. (2008). Genre relations: Mapping culture. London: Equinox.

Mills, N. A., \& Péron, M. (2009). Global simulation and writing self-beliefs of college intermediate French students. International Journal of Applied Linguistics, 156, 239-273.

Ochs, E. (1993). Constructing social identity: A language socialization perspective. Research on Language and Social Interaction, 26, 287-306.

Pavlenko, A. (2001). Multilingualism, second language learning, and gender. New York: Walter De Gruyter.

Sannino, A., Daniels, H., \& Gutiérrez, C. (Eds.) (2009). Learning and expanding with activity theory. New York: Cambridge University Press.

Sawchuk, P., Duarte, N., \& Elhammoumi, M. (Eds.) (2006). Critical perspectives on activity: Explorations across education, work, \& everyday life. New York: Cambridge.

Schegloff, E. A., Koshik, I., Jacoby, S., \& Olsher, D. (2002). Conversation analysis and applied linguistics. Annual Review of Applied Linguistics, 22, 3-31.

Schleppegrell, M. (2004). The language of schooling: A functional linguistic perspective. Mahwah, NJ: Lawrence Erlbaum Associates.

Skehan, P. (2003). Focus on form, tasks and technology. Computer Assisted Language Learning, 16, $391-411$.

Smith, B. (2003). Computer-mediated negotiated interaction: An expanded model.Modern Language Journal, 87, 38-58.

Stivers, T., Enfield, N. J., Brown, P., Englert, C., Hayashi, M., Heinemann, T., Hoymann, G., Rossano, F., De Ruiter, J.P., Yoon, K.E., \& Levinson, S.C. (2009). Universals and cultural variation in turntaking in conversation. Proceedings of the National Academy of Sciences of the United States of America, 106(26), 10587-10592.

Thorne, S. L. (2008). Mediating technologies and second language learning. In Leu, D., Coiro, J., Lankshear, C., \& Knobel, M. (Eds.), Handbook of Research on New Literacies (pp. 417-449). Mahwah, $\mathrm{NJ}$ : Lawrence Erlbaum.

Thorne, S. L., Black, R. W., \& Sykes, J. (2009). Second language use, socialization, and learning in internet interest communities and online games. Modern Language Journal, 93, 802-821.

Thorne, S. L. \& Reinhardt, J. (2008). "Bridging activities," new media literacies, and advanced foreign language proficiency. CALICO Journal, 25, 558-572.

Ware, P., \& Kramsch, C. (2005). Toward an intercultural stance: Teaching German and English through telecollaboration. Modern Language Journal, 89, 190-205.

Warschauer, M. and Healey, D. (1998). Computers and language learning: An overview. Language Teaching, 31: 57-71.

Wenger, E. (1998). Communities of practice: Learning, meaning, and identity. Cambridge: Cambridge University Press. 


\section{AUTHORS' BIODATA}

Steven L. Thorne holds faculty appointments in the Department of World Languages \& Literatures at Portland State University and in the Department of Applied Linguistics at the University of Groningen, The Netherlands. His interests and research include cultural-historical and usage-based approaches to language development, language use and learning in social media and online gaming environments, and theoretical investigations of language, intercultural communication, and development.

Bryan Smith is Assistant Professor of English at Arizona State University in Tempe, Arizona. His major research interest is the intersection of SLA theory and CALL.

\section{AUTHORS' ADDRESSES}

Steven L. Thorne

Department of World Languages \& Literatures

Portland State University

PO Box 751, WLL-NH 491

Portland, OR 97207-0751

United States of America

$\&$

Department of Applied Linguistics

University of Groningen

Oude Kijk in 't Jatstraat 26

9712 EK Groningen

The Netherlands

Email: stevenlthorne@gmail.com

Bryan Smith, Ph.D.

Assistant Professor of English

Arizona State University

Department of English

Box 870302

Tempe, AZ 85287-0302

Email: bryansmith@asu.edu

SKYPE @ davidbryansmith 